Subscriber access provided by Caltech Library

\title{
Article
}

\section{Unified Theory of Vapor-Wall Mass Transport in Teflon-Walled Environmental Chambers}

Yuanlong Huang, Ran Zhao, Sophia M. Charan, Christopher M Kenseth, Xuan Zhang, and John H. Seinfeld

Environ. Sci. Technol., Just Accepted Manuscript • DOI: 10.1021/acs.est.7b05575 • Publication Date (Web): 29 Jan 2018

Downloaded from http://pubs.acs.org on January 30, 2018

\section{Just Accepted}

"Just Accepted" manuscripts have been peer-reviewed and accepted for publication. They are posted online prior to technical editing, formatting for publication and author proofing. The American Chemical Society provides "Just Accepted" as a free service to the research community to expedite the dissemination of scientific material as soon as possible after acceptance. "Just Accepted" manuscripts appear in full in PDF format accompanied by an HTML abstract. "Just Accepted" manuscripts have been fully peer reviewed, but should not be considered the official version of record. They are accessible to all readers and citable by the Digital Object Identifier (DOI®). "Just Accepted" is an optional service offered to authors. Therefore, the "Just Accepted" Web site may not include all articles that will be published in the journal. After a manuscript is technically edited and formatted, it will be removed from the "Just Accepted" Web site and published as an ASAP article. Note that technical editing may introduce minor changes to the manuscript text and/or graphics which could affect content, and all legal disclaimers and ethical guidelines that apply to the journal pertain. ACS cannot be held responsible for errors or consequences arising from the use of information contained in these "Just Accepted" manuscripts. 


\title{
Unified Theory of Vapor-Wall Mass Transport in Teflon-Walled Environmental Chambers
}

\author{
Yuanlong Huang, ${ }^{\dagger}$ Ran Zhao, ${ }^{\ddagger}$ Sophia M. Charan ${ }^{\ddagger}$ Christopher M. Kenseth, ${ }^{\ddagger}$ \\ Xuan Zhang, and John H. Seinfeld*,‡,§ \\ $\dagger$ †ivision of Geological and Planetary Sciences, California Institute of Technology, \\ Pasadena, CA, USA, 91125 \\ $\ddagger$ Division of Chemistry and Chemical Engineering, California Institute of Technology, \\ Pasadena, CA, USA, 91125 \\ \National Center for Atmospheric Research, Boulder, CO, USA, 80301 \\ $\S$ Division of Engineering and Applied Science, California Institute of Technology, \\ Pasadena, CA, USA, 91125 \\ E-mail: seinfeld@caltech.edu \\ Phone: +1 626395 4635. Fax: +1626568 8743

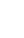


on the rate of wall deposition of more than 90 compounds. Semi-empirical relationships between key parameters in the model and vapor molecular properties are derived, which can be used to predict the fate of gas-phase vapor in the chamber under dry conditions.

\section{Introduction}

The environmental chamber is a principal laboratory system used to study the formation, properties, and evolution of secondary organic aerosol (SOA). ${ }^{1}$ The typical material from which chambers are constructed is Teflon film (fluorinated ethylene propylene, FEP). The process of SOA formation involves oxidation of a volatile organic compound (VOC) to generate low-volatility gas-phase products that subsequently condense into the aerosol phase. It has been established that these oxidized products may also partition into the Teflon chamber walls. ${ }^{2-16}$ Such vapor-wall loss reduces the potential yield of SOA and must be accounted for in analysis of experiments. Current treatments of vapor-wall deposition in chambers consider the FEP film as an infinite medium into which vapor molecules dissolve.

The extent of partitioning of oxidized organic species typical of SOA into Teflon film has been studied experimentally by introducing species individually into a chamber and measuring their rate of decay from wall uptake. The uptake has been characterized by the timescale required to approach vapor-wall equilibrium $\left(\tau_{w}\right)$. Previous studies indicate that $\tau_{w}$ can be competitive with the timescales of other processes occurring in the chamber, such as the rate of VOC oxidation and the timescale associated with vapor-particle partitioning. ${ }^{4,14}$ The timescale $\tau_{w}$ is governed by gas-phase diffusion through the boundary layer adjacent to the chamber wall, followed by uptake into the wall itself. Two major studies of vaporwall uptake of individual organic species typical of VOC oxidation products have reported significantly different time scales for vapor uptake, namely $\tau_{w} \sim 10 \min ^{12}$ and $\tau_{w} \sim 10$ h. $^{10}$ Possible reasons for the observed discrepancy in vapor-wall uptake rates include differences in the particular chemical systems studied or in the experimental protocol itself. The goal of 
the present work is to formulate and evaluate experimentally a unified theory of vapor-wall mass transport and uptake in Teflon-walled environmental chambers.

\section{Two-Layer Kinetic Sorption Model}

We introduce a two-layer kinetic sorption model (Fig. 1A), inspired by that proposed by Crank, ${ }^{17}$ to explain the stress-dependent diffusion of vapor molecules into polymer film. In the two-layer model, after traversing a gas-phase boundary layer, vapor molecules enter a sharp, swollen outer layer in the Teflon that is thought to be stress-free, in which equilibrium with the gas phase is established relatively rapidly. It is estimated that a pseudo-steady state profile in the gas-phase boundary layer is achieved on a timescale of order $10 \mathrm{~s}$ (Supporting Information, SI. I). Vapor molecules absorbed into the outer polymer layer (denoted the "Surface layer" in Fig. 1A) then slowly diffuse into the interior of the polymer film (the "Inner layer" in Fig. 1A) by breaking inter-chain bonds, impeded by the stress exerted by the polymer network.

\section{Surface Layer}

The Teflon FEP film is treated as a solution into which the molecules dissolve. Matsunaga and Ziemann ${ }^{3}$ proposed that vapor-wall partitioning equilibrium can be represented by an effective organic mass concentration of the wall itself, $C_{w}$, by analogy to the effective aerosol mass concentration used in describing vapor-particle uptake. ${ }^{18}$ Here, we introduce $C_{w}$ and $C_{w}^{\prime}$, respectively, to distinguish between the compound-independent and -dependent equivalent mass concentration of the Teflon wall. These quantities are related by $C_{w}^{\prime}=\frac{C_{w}}{\gamma^{\infty}}$, where $\gamma^{\infty}$ is the activity coefficient of the solute vapor dissolved in an infinitely dilute solution of Teflon film. The compound-dependent $C_{w}^{\prime}$ reflects, therefore, the effect of the compound's activity in Teflon film. The process of partitioning into $C_{w}$ corresponds to the surface layer absorption. 
It is advantageous to define an effective thickness of the surface layer, $L_{e}^{\prime}$. $L_{e}^{\prime}$ is related to $C_{w}^{\prime}$ by $L_{e}^{\prime}=\frac{V}{A} \frac{C_{w}^{\prime}}{\rho_{w}}$, where $V$ and $A$ are the volume and surface area of the chamber, respectively, and the density of FEP film ${ }^{19}$ is $\rho_{w}=2150 \mathrm{~kg} \mathrm{~m}^{-3}$. Note that this effective thickness $L_{e}^{\prime}$ is related to the physical thickness of the surface layer $L_{e}$ by $L_{e}^{\prime}=\frac{L_{e}}{\gamma^{\infty}}$. Measurements of $C_{w}$ suggest that $L_{e}$ is of order $1 \mathrm{~nm},{ }^{3,9,12}$ corresponding to a sharp air-polymer interface. This behavior is similar to that of a typical vapor-liquid interface, wherein the density increases sharply from the bulk vapor to the bulk liquid over a distance of order 1 $\mathrm{nm}(10-20$ nominal molecular diameters $) .{ }^{20}$ For water molecules, this distance is $\sim 3.3-$ $8.4 \AA .{ }^{21}$ For Teflon film, in determining $C_{w}^{\prime}$, Matsunaga and Ziemann ${ }^{3}$ assumed an effective molecular weight of Teflon film of $200 \mathrm{~g} \mathrm{~mol}^{-1}$; we adopt this assumption here, for which the effective Teflon molecular diameter is $0.54 \mathrm{~nm}$. We tentatively take $L_{e}=5 \mathrm{~nm}$, corresponding to a value of $C_{w}=32.2 \mathrm{mg} \mathrm{m}^{-3}$ (assuming $\gamma^{\infty}=1$ and $\frac{A}{V}=3 \mathrm{~m}^{-1}$ ), consistent with the suggestions by Krechmer et al. ${ }^{12}$ and Yeh and Ziemann. ${ }^{9}$ The molecular diffusivity in the swollen and stress-free surface layer, that is of order $10^{-13} \mathrm{~m}^{2} \mathrm{~s}^{-1},{ }^{22}$ establishes a timescale of $\sim 1$ ms to achieve concentration uniformity within the surface layer.

A key parameter in the kinetic sorption model is the vapor-wall equilibrium constant, $K_{w}$, similar to a Henry's law constant. The dimensionless $K_{w}=\frac{\rho_{w}}{\gamma^{\infty} c^{*}} \frac{M W_{v o c}}{M W_{w}}$, where $M W_{v o c}$ and $M W_{w}$ are the mean molecular weights of the VOC vapor and FEP film, respectively, and $c^{*}$ is the saturation mass concentration of the vapor. Typically, the activity coefficient of a compound in Teflon film, $\gamma^{\infty}$, is the only unknown parameter in the expression for $K_{w}$. Limited information exists to constrain the value of $\gamma^{\infty}$, and the activity coefficient $\gamma^{\infty}$ is often assumed to be unity. ${ }^{3,9,12}$ Within the consistent model framework developed here, $\gamma^{\infty}$ is defined as the ratio of the physical thickness of the surface layer, $L_{e}$, to the effective thickness, $L_{e}^{\prime}$, i.e. $\gamma^{\infty}=\frac{L_{e}}{L_{e}^{\prime}}$. If $\gamma^{\infty}=1$, the FEP film behaves as an ideal solution. If $\gamma^{\infty}>1$, the vapor molecules prefer to remain in the gas phase; if $\gamma^{\infty}<1$, vice versa. Values of $\gamma^{\infty}$ for a wide variety of compounds calculated from the literature $3,5,9,12$ as a function of $c^{*}$ estimated by EVAPORATION ${ }^{23,24}$ as shown in Fig. S2-A and Table 1 indicates that $\gamma^{\infty}>$ 
1. The inverse linear relationship between $\gamma^{\infty}$ and $c^{*}$ suggests that FEP polymer is not generally hospitable for VOCs. This behavior, however, does not conflict with the presence of low volatility compounds in the Teflon film, since the vapor-wall equilibrium constant depends more strongly on $c^{*}$ than $\gamma^{\infty}$, such that compounds with lower $c^{*}$ will haver higher $K_{w}$ values (see Table 1 for dependence of $\gamma^{\infty}$ on $c^{*}$ ). Furthermore, the equilibrium fraction of solute remaining in the gas phase, $F_{g}$, (Fig. S2-B) is consistent with the observation that less volatile compounds tend to reside preferentially in the wall.

\section{Inner Layer}

The magnitude of the inner layer (Fig. 1) effective diffusivity, $\mathcal{D}_{\text {eff }}$, is key to determining the temporal behavior of the bulk gas-phase concentration, $C_{g}^{b}(t)$, in a sufficiently long-duration experiment $(\sim 10 \mathrm{~h})$. $\mathcal{D}_{\text {eff }}$ is considered to be influenced by the existence of FEP film in a glassy state, a coexistence of liquid and solid states, the latter of which comprises immobile micro-voids. ${ }^{25}$ Dual sorption theory ${ }^{26}$ asserts that whereas free molecules can diffuse through the liquid layer, deeper diffusion must satisfy the Langmuir adsorption isotherm on the inner surface of local micro-voids. ${ }^{26}$ As a result, the molecular diffusivity in polymer is lower than that in pure liquid $\left(10^{-13}-10^{-9} \mathrm{~m}^{2} \mathrm{~s}^{-1}\right) .{ }^{27}$ The overall $\mathcal{D}_{\text {eff }}$ of molecules absorbed in the Teflon inner layer is of order $10^{-22}-10^{-17} \mathrm{~m}^{2} \mathrm{~s}^{-1}$, well within the range of semi-solid diffusivities. ${ }^{28}$ By fitting time-dependent Teflon uptake rates of a variety of species, one can estimate the $\mathcal{D}_{\text {eff }}$ values.

\section{Governing Equations Describing Uptake of Vapor Molecules in the}

\section{Two-Layer Model}

The mass transport coefficients across the gas-phase boundary layer and through the vapor-

Teflon interface (Fig. 1) can be written as $v_{e}=\frac{2}{\pi} \sqrt{k_{e} \mathcal{D}_{g}}$ and $v_{c}=\frac{\alpha_{w} \omega}{4}$, respectively, where $k_{e}$ is the eddy diffusivity coefficient for mixing in the chamber, $\mathcal{D}_{g}$ is the vapor molecular 
diffusivity in air, $\alpha_{w}$ is the vapor-wall accommodation coefficient (see discussion in SI. II), and $\omega$ is the vapor molecular mean speed. From mass transfer resistance theory, the overall mass transport coefficient across the gas-phase boundary layer and the air-Teflon interface is $v_{l}=\left(\frac{1}{v_{e}}+\frac{1}{v_{c}}\right)^{-1}$. For quasi-steady state gas-phase boundary layer diffusion (see discussion in SI. I), the bulk gas-phase mass flux $J_{b}\left(\mu \mathrm{g} \mathrm{s}^{-1}\right)$ to the Teflon surface is:

$$
J_{b}=A v_{l}\left(C_{g}^{b}(t)-\frac{C_{s}(t)}{K_{w}}\right)
$$

where $C_{g}^{b}$ is the gas-phase concentration in the bulk chamber and $C_{s}$ is the concentration of vapor dissolved in the wall surface layer. The mass balance for $C_{g}^{b}$ involving vapor-wall mass transfer and gas-phase chemical reactions is:

$$
\frac{d C_{g}^{b}(t)}{d t}=-\left(\frac{A}{V}\right) v_{l}\left(C_{g}^{b}(t)-\frac{C_{s}(t)}{K_{w}}\right)+\sum^{i} R_{i}
$$

where $\sum^{i} R_{i}$ represents the net generation or consumption of the species by chemical reaction.

Within the Teflon surface layer, the diffusive flux, $J_{d}\left(\mu \mathrm{g} \mathrm{s} \mathrm{s}^{-1}\right)$, at the surface layer-inner layer boundary is:

$$
J_{d}=-\left.A \mathcal{D}_{\text {eff }} \frac{\partial C_{i}(x, t)}{\partial x}\right|_{x=L_{e}}
$$

where $C_{i}$ is the concentration of vapor molecules in the wall inner layer. Time-dependent mass conservation for $C_{s}$ is given by:

$$
\frac{d C_{s}(t)}{d t}=\frac{v_{l}}{L_{e}}\left(C_{g}^{b}(t)-\frac{C_{s}(t)}{K_{w}}\right)+\left.\frac{\mathcal{D}_{\mathrm{eff}}}{L_{e}} \frac{\partial C_{i}(x, t)}{\partial x}\right|_{x=L_{e}}
$$

Diffusion of the dissolved solute in the inner Teflon layer obeys:

$$
\frac{\partial C_{i}(x, t)}{\partial t}=\mathcal{D}_{\mathrm{eff}} \frac{\partial^{2} C_{i}(x, t)}{\partial x^{2}}
$$


Associated initial and boundary conditions are:

$$
\begin{aligned}
& C_{g}^{b}(0)=C_{g 0}^{b} ; \quad C_{s}(0)=C_{s 0} ; \\
& C_{i}(x, 0)=0 ; \quad C_{i}(0, t)=C_{s}(t) ; \quad C_{i}(\infty, t)=0 ;
\end{aligned}
$$

$C_{g 0}^{b}$ and $C_{s 0}$ are appropriate initial concentrations. For example, $C_{s 0}=0$ corresponds to a pristine chamber condition, while $C_{g 0}^{b}=\frac{C_{s 0}}{K_{w}}$ applies if the bulk gas-phase and surface layer concentrations are at equilibrium at the beginning of an experiment. The boundary condition as $x \rightarrow \infty$ expresses the consequence of the slow diffusion in the inner layer relative to the overall extent of the layer itself. If $\mathcal{D}_{\text {eff }}$ is sufficiently small such that penetration into the inner layer is negligible over an experiment, the mass conservation equations reduce to a single-layer sorption model, in which the corresponding vapor-wall equilibrium timescale $\left(\tau_{\text {vwe }}\right)$ is:

$$
\tau_{v w e}=\left(\frac{A}{V}\right)^{-1}\left(1+\frac{V}{K_{w} L_{e} A}\right)^{-1} v_{l}^{-1}
$$

Table 1 summarizes the key parameters that represent vapor-wall deposition in chamber experiment simulations.

\section{Aqueous Film Model}

Under sufficiently high relative humidity conditions $(\mathrm{RH}>90 \%)$, it is assumed that an aqueous film of thickness $L_{a q}$ exists on the chamber wall (Fig. 1B). Since the diffusivity of vapor molecules in water $\mathcal{D}_{a q}$ is $\sim 1 \times 10^{-9} \mathrm{~m}^{2} \mathrm{~s}^{-1},{ }^{29}$ the estimated timescale $\left(\frac{L_{a q}^{2}}{\mathcal{D}_{a q}}\right)$ for the dissolved vapor concentration to reach uniformity in this thin layer of water is sufficiently small (e.g. $\sim 10^{-1} \mathrm{~s}$ if $L_{a q}=10 \mu \mathrm{m}$ ) such that the rate-limiting step for uptake is either gas-phase boundary layer diffusion or interfacial accommodation at the air-water interface.

Since oxidized VOCs tend to be polar molecules, $\gamma^{\infty}$ in aqueous solution should be smaller than that in Teflon polymer solution, such that partitioning in the aqueous phase is preferred over the polymer phase. Thus, in this case, a reasonable assumption is that vapor 
partitioning does not proceed beyond the thin water film on the Teflon surface.

For this single-layer model, EQ. (7) can be directly applied to the aqueous film uptake, replacing $K_{w}$ and $L_{e}$ with the Henry's law constant $H$ and $L_{a q}$, respectively. As described in SI. II, based on measured timescale and equilibrium constants, it is possible to estimate the accommodation coefficient of the water surface.

\section{Experimental Study of Vapor-Wall Uptake}

To study vapor-wall interaction, we either (i) generated the compounds in situ by VOC oxidation in the chamber, ${ }^{10,12,30-34}$ or (ii) injected the compounds of interest (purchased or synthesized) into the chamber. ${ }^{2,3,9,28,35-38}$ The two-layer kinetic model is applied to two laboratory data sets from the Caltech Environmental Chamber $\left(24 \mathrm{~m}^{3}, \frac{A}{V} \sim 2 \mathrm{~m}^{-1}\right)$ on the dynamics of vapor-wall deposition of individual compounds: (i) Zhang et al. ${ }^{10}$ corresponding to in situ generation and (ii) deposition measurements of alcohols (1-hexanol 98\%, 1-heptanol 98\%, 1-octanol $\geq 99 \%$, 1-nonanol 98\%, 1-decanol $\geq 99 \%$, 1-undecanol $\geq 97.5 \%$, and 1-dodecanol 98\%), aromatics (toluene $99.8 \%, m$-xylene $\geq 99 \%$, $o$-xylene $98 \%$, and 1,3,5trimethylbenzene $98 \%$ ), alkanes ( $n$-dodecane $\geq 99 \%, n$-tridecane $\geq 99 \%, n$-tetradecane $\geq$ 99\%, $n$-octylcyclohexane 98\%), and biogenics (isoprene 99\%, methacrolein 95\%, methyl vinyl ketone $99 \%$, and $\alpha$-pinene $\geq 99 \%$ ) (all purchased through Sigma-Aldrich) by direct injection.

In the experiments conducted by Zhang et al. ${ }^{10}$ in situ oxidation of $\alpha$-pinene, $n$-dodecane, toluene, and isoprene were carried out under high- and low- $\mathrm{NO}_{x}$ conditions, with oxidation periods varying from 1 to $7 \mathrm{~h}$. A customized $\mathrm{CF}_{3} \mathrm{O}^{-}$-CIMS ${ }^{39}$ (chemical ionization mass spectrometry) was used to monitor the vapor-wall decay rates. Refer to Zhang et al. ${ }^{10}$ for more experimental details. In the direct injection experiments, a bulb containing 10 to 50 $\mu \mathrm{L}$ of pure or mixed liquid VOCs was maintained at $65^{\circ} \mathrm{C}$ (as well as the $50 \mathrm{~cm}$ stainless injection line, $3 / 8 \mathrm{in}$. OD) to ensure complete injection at a flow rate of $5 \mathrm{~L} \mathrm{~min}^{-1}$ of clean air $(\sim 100 \mathrm{ppb}$ in the chamber, several orders of magnitude lower than the saturation vapor 
pressure). Before each injection, the chamber has been flushed with clean air at a flow rate of $370 \mathrm{~L} \mathrm{~min}^{-1}$ for $24 \mathrm{~h}$ at $45^{\circ} \mathrm{C}$. The injection period varied from minutes (biogenics) to hours (alcohols). After the injection period, 5 pulse injections of clean air were used to actively mix the chamber without significantly altering its volume. The chamber is considered to be well mixed $\sim 5$ min after this operation, which is especially relevant for compounds with short injection periods. A series of RH-dependent studies was carried out in the chamber under $8 \% \pm 5 \%, 50 \% \pm 5 \%$ and, $80 \% \pm 5 \% \mathrm{RH}$ at $20^{\circ} \mathrm{C}$.

Over $\sim 18 \mathrm{~h}$ in the dark, a gas chromatograph with flame ionization detector (GC/FID, Agilent $6890 \mathrm{~N}$ ) was used to monitor the temporal concentration changes at a continuous sampling flow rate of $0.29 \mathrm{~L} \mathrm{~min}^{-1}$ through a perfluoroalkoxy (PFA) Teflon tube $(1 / 4 \mathrm{in}$. OD, 3/16 in. ID, and $2.0 \mathrm{~m}$ length). Pagonis et al. ${ }^{40}$ note that use of a PFA Teflon tube induces a response time lag for "sticky" compounds; the continuous flow through the sampling tube and lower sampling time resolution $(\sim 10 \mathrm{~min})$ act to smooth this effect. A HP-5 column $(30 \mathrm{~m} \times 0.32 \mathrm{~mm}$ ID $\times 0.25 \mu \mathrm{m}$ film thickness $)$ was used for alcohols, aromatics, alkanes, and $\alpha$-pinene, and a HP-PLOT Q column $(15 \mathrm{~m} \times 0.53 \mathrm{~mm}$ ID $\times 40 \mu \mathrm{m}$ film thickness $)$ was used for isoprene, methacrolein (MACR), and methyl vinyl ketone (MVK). For mixtures, the GC temperature ramping procedure was adjusted to obtain full peak resolution. It is challenging to clearly define the start time for GC measurements of compound dark decay. We ignore the first 3 to 5 data points of the GC measurements, which is $\sim 1 \mathrm{~h}$ after injection, on the assumption that the vapor concentrations in the the gas phase and the surface layer have reached equilibrium.

Additionally, studies of in situ 20 s-pulse generated compounds ${ }^{12}$ from isoprene oxidation under $8 \% \pm 5 \%, 50 \% \pm 5 \%$ and $>90 \% \mathrm{RH}$ were carried out. When $\mathrm{RH}>90 \%$, an aqueous film was introduced to the surface of Teflon film by injecting water vapor into the chamber at $30^{\circ} \mathrm{C}$ until the $\mathrm{RH}$ reached $\sim 80 \%$ and cooling to $20^{\circ} \mathrm{C}$ to facilitate a uniform water film condensation on the wall, as evidenced visually by the blurry appearance of the chamber. Isoprene $(\sim 200 \mathrm{ppb}), \sim 1.2 \mathrm{ppm}$ NO (Airgas, $500 \mathrm{ppm} \pm 1 \%$ ), and $\sim 1.2 \mathrm{ppm} \mathrm{CH}_{3} \mathrm{ONO}$ 
(synthesized following Taylor et al. ${ }^{41}$ ) were injected to the chamber, respectively. UV lights were turned on for $20 \mathrm{~s}\left(\mathrm{j}_{\mathrm{NO}_{2}}=0.0044 \mathrm{~s}^{-1}\right)$, and no nucleation was observed after lights off. Oxidation products were monitored with a custom-modified $\mathrm{I}^{-}$-CIMS ${ }^{42}$ with a $2 \mathrm{~L} \mathrm{~min}^{-1}$ sampling rate through $1 / 4$ in. PFA tube. A permeation tube with pure liquid $\mathrm{CH}_{3} \mathrm{I}$ (SigmaAldrich, 99\%) was used for reagent ion generation in $\mathrm{I}^{-}$-CIMS, where vapor molecules $\mathrm{X}$ are detected as the cluster $\left(\mathrm{X} \cdot \mathrm{I}^{-}\right)$.

In the two-layer kinetic model simulation, the values of $k_{e}$ and $\mathcal{D}_{g}$ used are $0.075 \mathrm{~s}^{-1}$ and $5 \times 10^{-6} \mathrm{~m}^{2} \mathrm{~s}^{-1}$, respectively, for all compounds. ${ }^{6}$ The accommodation coefficient $\alpha_{w}$ is calculated by a fitted empirical equation based on literature data (Table 1 and Fig. S3, see SI. II for details). Activity coefficients for the compounds studied in Zhang et al. ${ }^{10}$ are predicted by the equation in Table 1 and Fig. S2-A. Since the oxidation period in Zhang et al. ${ }^{10}$ varied from 1 to $7 \mathrm{~h}$, it is reasonable to assume that an equilibrium state between

the bulk chamber and the surface layer had been reached, i.e. $C_{g}^{b}=\frac{C_{s}}{K_{w}}$, when lights are off. This assumption excludes the oxidation period from the fitting process. We will address subsequently the effect of the oxidation period on the temporal profile of bulk concentration.

\section{Results and Discussion}

\section{Effect of Oxidation Period on Vapor-Wall Partitioning}

To study vapor-wall interaction, the species of interest is introduced to the chamber by either direct injection or in situ generation. During injection, the more volatile compounds generally require less time to inject but achieve wall partitioning more slowly (e.g. $n$-alkanes ${ }^{3}$ ), whereas less volatile compounds require a longer injection time, during which the bulk chamber and the wall may have already reached equilibrium when injection is completed. Even though the injection period can be shortened by heating the bulb and the injection line,${ }^{3,9}$ for passively mixed chambers the chamber mixing timescale may be the limiting factor to obtain a wellmixed concentration in the chamber. This mixing issue is avoided with in situ generation 
of oxidation products. Ideally, the VOC oxidation period is short, so as to approximate as closely as possible a pulse input of oxidation products. ${ }^{12}$ This is important, as the anticipated equilibration time between generation in the chamber and absorption by the surface layer of Teflon is of order $10^{3}$ s. $^{12}$ However, generation of detectable concentration of products usually requires a relatively long oxidation time $\left(\mathrm{OH}\right.$ concentration is typically $\sim 10^{6}$ molecules $\mathrm{cm}^{-3}$ ), during which period equilibrium between the bulk chamber and the surface layer is likely to be achieved.

An idealized kinetic model is useful to describe the interplay between in situ oxidation and the approach to vapor-wall equilibrium. Let us assume that the VOC oxidation can be represented by the first-order reaction $\mathrm{G} \stackrel{\mathrm{k}_{0}}{\longrightarrow} \mathrm{X}$, where $\mathrm{G}$ is the VOC precursor, $\mathrm{X}$ is the oxidation product (i.e. the bulk concentration $C_{g}^{b}(t)$ in Eq. $(2)$ ), and $\mathrm{k}_{0}$ is an effective firstorder rate constant. Since diffusion in the inner layer of the Teflon film is sufficiently slow, it is reasonable to ignore the inner layer uptake of the vapors during the oxidation period, i.e. the second term in Eq. (4). By multiplying a scaling factor $\frac{A}{V} L_{e}$ to $C_{s}(t)$ in Eq. (4), the system can be represented kinetically by $\mathrm{G} \stackrel{\mathrm{k}_{0}}{\longrightarrow} \mathrm{X} \underset{\mathrm{k}_{-1}}{\stackrel{\mathrm{k}_{1}}{\rightleftharpoons}} \mathrm{Y}$, where $\mathrm{Y}=\frac{A}{V} L_{e} C_{s}(t), \mathrm{k}_{1}=\frac{A}{V} v_{l}$, and $\mathrm{k}_{-1}=\frac{1}{L_{e} K_{w}} v_{l}$. The equilibrium constant for this system is $K_{e q}=\frac{\mathrm{k}_{1}}{\mathrm{k}_{-1}}=K_{w} \frac{A}{V} L_{e}$. By this representation, vapor-wall partitioning during the VOC oxidation period is mathematically analogous to a classical equilibrium reaction system.

The departure from vapor-wall equilibrium at the end of the reaction period is defined by the normalized deviation $\epsilon=\frac{Y_{e}-Y_{0}}{Y_{e}}=\frac{X_{0}-X_{e}}{X_{e} K_{e q}}$, where $X_{0}$ and $Y_{0}$ are the concentrations of $\mathrm{X}$ and $\mathrm{Y}$ at the end of the oxidation period, and $X_{e}$ and $Y_{e}$ are the concentrations at equilibrium. Thus, a value of $\epsilon=0$ indicates that equilibrium has already been reached at the end of the oxidation period, whereas a value of $\epsilon$ close to 1 suggests that from the measured concentration change of $X$ one can derive the characteristic time scale and equilibrium constant for vapor-wall deposition. Note that it is necessary only to focus on species X since that is the compound being measured. An analytical solution for the timedependent dynamics of this kinetic system is given in SI. III. 
For the compounds examined in this study and by Zhang et al., ${ }^{10}$ the oxidation period $\tau_{\text {ox }}$ varies from $\sim 10 \mathrm{~s}$ to $\sim 7 \mathrm{~h}$. Assuming that $5 \%$ of the precursor $\mathrm{G}$ is consumed at the end of the oxidation period, the reaction rate constant $\mathrm{k}_{0}$ follows the relationship $\tau_{\mathrm{ox}} \mathrm{k}_{0}=0.05$. The forward rate constant $\mathrm{k}_{1}$ is determined by the mixing time scale in the chamber $\left(k_{e}\right)$, as well as the surface accommodation coefficient $\left(\alpha_{w}\right)$. Using $k_{e}=0.075 \mathrm{~s}^{-1}, \mathcal{D}_{g}=5 \times 10^{-6} \mathrm{~m}^{2}$ $\mathrm{s}^{-1}$, and $\alpha_{w}=10^{-5}$ (discussion in SI. II suggests that most of the compounds studied here are located in the gas-phase boundary layer diffusion regime, where the critical $\alpha_{w} \sim 10^{-6}$, for simplicity, a fixed value of $10^{-5}$ for $\alpha_{w}$ is assumed here), a value of $\mathrm{k}_{1}=4.02 \times 10^{-4}$ $\mathrm{s}^{-1}$ is obtained, which is of the same order of magnitude as the values reported in the wall deposition study by Krechmer et al.. ${ }^{12}$ A contour plot (Fig. 2) of $\epsilon$ as a function of vapor-wall equilibrium constant, $K_{w} \frac{A}{V} L_{e}$, and oxidation period, $\tau_{\text {ox }}$, indicates that the majority $(\sim 75 \%)$ of the compounds studied in Zhang et al. ${ }^{10}$ had already reached vapor-wall equilibrium at the end of the relatively lengthy oxidation period. In such a case, it is reasonable to estimate the diffusivity in the inner layer by assuming equilibrium between the bulk chamber and the surface layer. The small value of the wall accommodation coefficient reported by Zhang et al. ${ }^{10}$ likely represents a combination of surface accommodation and inner layer diffusion. Fig. 2 shows explicitly the effect of the length of the oxidation period on the surface-layer equilibrium process, since inner-layer diffusion will dominate the dynamics of the vapor sink in a long-duration oxidation experiment.

\section{Diffusion in Teflon Polymer}

The inferred diffusivities $\mathcal{D}_{\text {eff }}$ of species dissolved in Teflon film obtained by fitting data to the two-layer model as a function of the molecular saturation concentration $c^{*}$ are shown in Fig. $3 \mathrm{~A}$. $\mathcal{D}_{\text {eff }}$ values are in the range of $10^{-22}-10^{-17} \mathrm{~m}^{2} \mathrm{~s}^{-1}$, which is of order $10^{6}$ smaller than those of small organic molecules in polymer film, ${ }^{22,27,43}$ a result that is consistent with the higher energy barrier for larger molecules. ${ }^{17,43} \mathrm{~A}$ transition state between solid and liquid diffusivities of this order of magnitude is well within the range of those in semi-solid organic 
aerosol particles. ${ }^{27}$

With the assumption that the molecular diffusivity in FEP film can be expressed as a function of molecular volume, we apply a semi-empirical equation to correlate the diffusivity as a function of vapor molecular volume $\left(\theta \text { in } \mathrm{cm}^{3} \mathrm{~mol}^{-1}\right)^{44}$ and vapor saturation concentration $\left(c^{*}\right.$ in $\left.\mu \mathrm{g} \mathrm{m}^{-3}\right) . c^{*}$ is used as the parameter that incorporates the contribution from different functional groups, and, as noted earlier, is estimated by the empirical routine EVAPORATION. ${ }^{23,24}$ The diffusivities obtained from the semi-empirical equation (Table 1) are shown in Fig. 3B. 95\% of the predicted diffusivities lie within an order of magnitude of those inferred $\mathcal{D}_{\text {eff }}$. The high order of negative molecular volume dependence is consistent with the expectation that the larger the molecule, the smaller the diffusivity. The critical volume in the semi-empirical equation $\left(110.9 \mathrm{~cm}^{3} \mathrm{~mol}^{-1}\right)$ can be viewed as a characteristic "hole" in the film; thus, small molecules only have to overcome the crosslinks between polymer chains. The fitted value of the critical volume is found to exceed those of most of the molecules studied previously; ${ }^{22,43}$ thus the semi-empirical relation given in Fig. $3 \mathrm{~B}$ cannot be used for molecules smaller than the critical volume. The diffusivity is found to be mildly dependent on vapor saturation concentration, reflecting the effect of the presence of functional groups (or molecular shape) on molecular diffusivity.

Diffusivities of vapor molecules in fresh and aged Teflon chambers have also been investigated. Though the absorption properties of the surface layer were reported to be unchanged in either fresh or aged Teflon chambers, ${ }^{3}$ by fitting experimental data in the Caltech chamber, ${ }^{10}$ we found that the inner layer diffusivity increased with use of chambers, consistent with the observations by Loza et al.. ${ }^{2}$ Such behavior could be attributed to alteration of inter-chain bonds, such that subsequent diffusion is characterized by internal stress relaxation. ${ }^{17,43}$ See discussion in SI.IV for additional details. 


\section{Humidity Effect}

For polymer film chambers, permeation of ubiquitous ambient water vapor through the film is possible given the small molecular volume and high diffusivity $\left(\sim 10^{-12} \mathrm{~m}^{2} \mathrm{~s}^{-1}\right)$ of water in such polymer films. ${ }^{45}$ The dissolution of water molecules in the Teflon film can exert an impact on the behavior of organic molecules therein. For hydrophilic compounds, the water could facilitate the absorption of the vapors into the film, while for hydrophobic compounds, it could exert a retarding effect. In the high humidity case, in which an aqueous film is hypothesized to be present on the Teflon surface (Panel B of Fig. 1), it is evident that hydrophilic compounds would dissolve in the aqueous film.

The limited studies of RH-dependent vapor-wall interaction in chambers that exist report that the vapor-wall loss rate increases at higher $\mathrm{RH}(>50 \%) .{ }^{2,35,37,38}$ It is notable that the compounds that have been studied in this regard are either reactive with water (e.g. IEPOX $^{35,37}$ ) or highly water soluble (e.g. $\mathrm{HCOOH}, \mathrm{H}_{2} \mathrm{O}_{2}{ }^{38}$ and glyoxal ${ }^{2}$ ). These observations are consistent with the existence of water molecules in the Teflon film facilitating the absorption of hydrophilic compounds. We used two experimental strategies to investigate the role of $\mathrm{RH}$ in vapor-wall interaction.

In the first class of experiments, we injected into the chamber at different $\mathrm{RH}$ levels several groups of compounds (alcohols, alkanes, aromatics, and biogenics) that are not highly water soluble and have relatively large molecular volume. A GC/FID was used to monitor the long-term dark decay of these compounds. The inferred diffusivities of the alcohols, alkanes, aromatics, and biogenics in Teflon are shown in Fig. S5, indicating that most of the diffusivities decrease as $\mathrm{RH}$ increases. It is expected that at high $\mathrm{RH}$, more water molecules dissolve in the Teflon film, such that intrusion of hydrophobic compounds is hindered.

Second, we carried out the same experimental protocol as that of Krechmer et al. ${ }^{12}$ based on an in situ pulse generation of oxidation products $\left(\mathrm{OH}\right.$ concentration is $\sim 10^{8}$ molecules $\left.\mathrm{cm}^{-3}\right)$. The temporal profiles of two isoprene oxidation products $\left(\mathrm{C}_{5} \mathrm{H}_{8} \mathrm{O}_{2}\right.$ and $\left.\mathrm{C}_{5} \mathrm{H}_{9} \mathrm{O}_{4} \mathrm{~N}\right)$ are shown in Fig. 4. Under dry conditions $(\mathrm{RH} \sim 5 \%), \mathrm{C}_{5} \mathrm{H}_{8} \mathrm{O}_{2}$ and $\mathrm{C}_{5} \mathrm{H}_{9} \mathrm{O}_{4} \mathrm{~N}$ exhibit 
essentially the same diffusivities as those observed by Zhang et al.. ${ }^{10}$ However, at RH $50 \%$, the two compounds behave differently; a faster decay rate is observed for $\mathrm{C}_{5} \mathrm{H}_{9} \mathrm{O}_{4} \mathrm{~N}$, which is likely attributable to hydrolysis of the compound containing a $-\mathrm{ONO}_{2}$ group. ${ }^{46}$ When a water film is introduced intentionally $(\mathrm{RH}>90 \%)$, the signals of both compounds decrease rapidly after the lights are off at almost the same rates, reaching a constant level for the next $8 \mathrm{~h}$. By fitting the data at $\mathrm{RH}>90 \%$ in Fig. 4 to the aqueous film model (Fig. 1B), a characteristic timescale is found to be $\sim 22 \mathrm{~min}$ for each compound, considerably faster than that due to inner layer diffusion under dry conditions. This value is in the range of vapor-wall equilibrium timescales $\left(\tau_{w}\right)$ reported by Krechmer et al. ${ }^{12}$ and Matsunaga and Ziemann. ${ }^{3}$ With an estimated chamber eddy diffusivity of $0.075 \mathrm{~s}^{-1},{ }^{6}$ the calculated accommodation coefficients of $\mathrm{C}_{5} \mathrm{H}_{8} \mathrm{O}_{2}$ and $\mathrm{C}_{5} \mathrm{H}_{9} \mathrm{O}_{4} \mathrm{~N}$ at the water surface are $3.06 \times 10^{-5}$ and $1.32 \times 10^{-5}$, respectively, consistent with gas-phase boundary layer mass transport being the rate-limiting step in the fast equilibrium sorption process.

The water film serves as a substantial reservoir given that both compounds are water active (soluble or reactive). By comparison, the inferred equilibrium constants, $K_{e q}$, for both compounds in the aqueous film exceed those in the dry Teflon film by factors of 186 and 21 , suggesting that the majority of the vapor molecules remain within the aqueous layer. The results of this aqueous film experiment are consistent with the conclusion that in SOA formation experiments under high $\mathrm{RH}$ conditions, the presence of a condensed water film on the wall will exacerbate vapor-wall loss of hydrophilic oxidation products.

\section{Mechanistic Representation of Vapor-Wall Deposition}

After the introduction of vapors into the chamber (either by injection or in situ generation), loss due to wall uptake is generally reported as first order. The experimental results reported here show that, in addition to the establishment of rapid equilibrium between the bulk gas phase and the surface layer of the chamber wall $\left(\tau_{\text {surf }} \sim 10^{3} \mathrm{~s}\right)$, inner layer diffusion as well as chemical reactions (e.g. hydrolysis) can lead to a continuous decay of the gas-phase 
vapors in the bulk chamber. This process can be represented kinetically by the following system: Source $\longrightarrow X \underset{\mathrm{k}_{-1}}{\stackrel{\mathrm{k}_{1}}{\rightleftharpoons}} \mathrm{Y} \stackrel{\mathrm{k}_{2}}{\longrightarrow} \mathrm{Z}$, where Source represents injection or in situ oxidation. Species $\mathrm{X}$ and $\mathrm{Y}$ represent the same compound in different phases, and species $\mathrm{Z}$ is the same compound in the third phase (e.g the inner layer in this case). Correspondingly, $\mathrm{k}_{2}$ represents either the first-order chemical reaction rate constant or the mass transfer coefficient. The forward and backward rate constants $\mathrm{k}_{1}$ and $\mathrm{k}_{-1}$ govern the approach to phase equilibrium of $\mathrm{X}$ and $\mathrm{Y}$.

When injection or in situ oxidation has ceased, the above dynamic system can be represented simply as $X \underset{\mathrm{k}_{-1}}{\stackrel{\mathrm{k}_{1}}{\rightleftharpoons}} \mathrm{Y} \stackrel{\mathrm{k}_{2}}{\longrightarrow} \mathrm{Z}$. If species $\mathrm{X}$ and $\mathrm{Y}$ have reached equilibrium, and if $\mathrm{k}_{2} \ll$ $\mathrm{k}_{1}+\mathrm{k}_{-1}$, a slow decay follows a rapid equilibrium. The time-dependent analytical solution of this kinetic system is presented in SI. VI. The apparent first-order decay rate constant, $k_{w}^{X}$, of species $\mathrm{X}$ exhibits the long-time asymptote $\frac{K_{e q}}{1+K_{e q}} \mathrm{k}_{2}$, where $K_{e q}=\frac{\mathrm{k}_{1}}{\mathrm{k}_{-1}}$ as defined above.

The net loss rate constant $k_{2}$ is a function of diffusivity $\mathcal{D}_{\text {eff. }}$. To obtain a relationship between $\mathrm{k}_{2}$ and $\mathcal{D}_{\text {eff }}$, an empirical equation can be fitted as shown in Fig. 5, where $\mathrm{k}_{2}$ and $\mathcal{D}_{\text {eff }}$ both emerge from fitting experimental data from the equilibrium reaction model and the twolayer diffusion model. For comparison, $\mathrm{k}_{2}$ values derived from reported apparent first-order loss rates, $k_{w}$, by the asymptotic relationship, $k_{w}=\frac{K_{e q}}{1+K_{e q}} \mathrm{k}_{2}$, and the inferred diffusivities are shown in Fig. 5. Many of these reported data points lie within the uncertainty of the empirical relationship. The small reported $\mathrm{k}_{2}$ values may be the result of different chamber conditions, ${ }^{30,32,35}$ or the use of the asymptote, since some of the data are from the observation within $2 \mathrm{~h}$ (as indicated in SI. VI, in the short time period, the apparent $k_{w}$ is small). Note that this empirical relationship does not account for the presence of heterogeneous reactions, which may change the value of $\mathrm{k}_{2}$. 


\section{Atmospheric Implications}

Teflon-walled laboratory chambers serve as the predominant system for the study of atmospheric SOA formation. Clear evidence exists for the deposition of VOC oxidation products on polymeric Teflon chamber walls. Such deposition removes products that would otherwise condense onto particles as SOA. Since the presence of wall deposition of vapors leads to an underestimate of the atmospheric SOA-forming potential of the parent VOC, data that have been influenced by such wall deposition will lead to an underprediction of SOA formation when extrapolated to the atmosphere.

The wall deposition process involves transport of vapor molecules from the core of the chamber to a boundary layer on the wall of the chamber, through which vapors are transported to the wall surface by a combination of molecular diffusion and macroscopic mixing. Vapor molecules diffuse into the Teflon polymer matrix by a process akin to that of uptake into a condensed phase. Observed rates of molecular uptake into Teflon polymer are found to be consistent with a model of the Teflon film consisting of two layers: (1) a thin surface layer into which vapor molecules penetrate first through the gas-phase boundary layer and second across the interface, over a time scale of order $10^{3} \mathrm{~s}$; and (2) a deeper layer of effectively semi-infinite extent into which the absorbed vapor molecules diffuse from the surface layer. The uptake rates by Teflon-walled chamber of over 90 individual organic vapor species are found to depend upon their molecular saturation vapor concentration $\left(c^{*}\right)$ and molecular size $(\theta)$.

Semi-empirical equations have been formulated to describe the absorptive properties $\left(\gamma^{\infty}\right.$ and $\alpha_{w}$ ) of the surface layer and the diffusivity in the inner layer of FEP film. Additional studies are needed to characterize the temperature effect on the vapor uptake process. Water molecules dissolved in the Teflon film provide extra sinks on the wall for hydrophilic compounds. Under sufficiently high RH conditions, where a thin film of condensed water is present on the Teflon surface, the wall becomes an increasingly competitive reservoir for hydrophilic compounds. The challenge is to design VOC oxidation chamber experiments 
under different $\mathrm{RH}$ levels so as to minimize vapor transport to the chamber walls. To better constrain the measured vapor-wall loss rate (e.g. the "apparent" first-order rate constant

$\left.k_{w}\right)$, recommended parameters and guidelines are given in Table 1, which can facilitate a comprehensive consideration of the sinks of gas-phase species in a typical SOA formation experiment. 
Table 1: Parameters Representing Vapor-Wall Deposition in Chambers ${ }^{a}$

\begin{tabular}{|c|c|}
\hline Parameter & Expression \\
\hline $\mathrm{k}_{1}$ : forward rate $\left(\mathrm{s}^{-1}\right)$ & $\left(\frac{A}{V}\right) v_{l}$ \\
\hline $\mathrm{k}_{-1}$ : backward rate $\left(\mathrm{s}^{-1}\right)$ & $\frac{10^{9}}{L_{e} K_{w}} v_{l}$ or $\left(\frac{A}{V}\right) v_{l} \frac{\gamma^{\infty} c^{*}}{10^{3} C_{w}} \frac{M W_{w}}{M W_{v o c}}$ \\
\hline $\begin{array}{l}\mathrm{k}_{2}: \text { first-order loss rate }\left(\mathrm{s}^{-1}\right) \\
L_{e}: \text { Surface layer thickness }(\mathrm{nm})\end{array}$ & Fig. 5 or from measurement ${ }^{b}$ \\
\hline$K_{w}$ : dimensionless equilibrium constant & $\frac{10^{9} \rho_{w}}{\gamma^{\infty} c^{*}} \frac{M W_{v o c}}{M W_{w}}$ \\
\hline$C_{w}$ : equivalent wall concentration $\left(\mathrm{mg} \mathrm{m}^{-3}\right)$ & $10.8\left(\frac{A}{V}\right)$ \\
\hline$\gamma^{\infty}:$ activity coefficient in FEP & $10^{3.299}\left(c^{*}\right)^{-0.6407}$ (Fig. S2-A) \\
\hline$v_{l}$ : wall deposition velocity $\left(\mathrm{m} \mathrm{s}^{-1}\right)$ & $\left(\frac{\pi}{2} \frac{1}{\sqrt{k_{e} \mathcal{D}_{g}}}+\frac{4}{\alpha_{w} \omega}\right)$ \\
\hline$\alpha_{w}$ : wall accommodation coefficient & $10^{-2.744}\left(c^{*}\right)^{-0.6566}$ (Fig. S3) \\
\hline $\mathcal{D}_{\text {eff }}$ : effective diffusivity in FEP film $\left(\mathrm{m}^{2} \mathrm{~s}^{-1}\right)$ & $10^{-17.05}(\theta-110.9)^{-1.695}\left(c^{*}\right)^{0.1831}$ \\
\hline $\begin{array}{l}\rho_{w}: \text { Teflon FEP density }{ }^{19}\left(\mathrm{~kg} \mathrm{~m}^{-3}\right) \\
c^{*} \text { : vapor saturation concentration }\left(\mu \mathrm{g} \mathrm{m}^{-3}\right)\end{array}$ & $\begin{array}{l}2150 \\
\text { species dependent }\left(\text { ref }^{23}\right)\end{array}$ \\
\hline$k_{e}$ : eddy diffusivity coefficient ${ }^{12}\left(\mathrm{~s}^{-1}\right)$ & $0.004+10^{-2.25}(V)^{0.74}$ \\
\hline$V:$ chamber volume $\left(\mathrm{m}^{3}\right)$ & chamber dependent \\
\hline A: chamber surface area $\left(\mathrm{m}^{2}\right)$ & chamber dependent \\
\hline $\mathcal{D}_{g}:$ diffusivity in gas phase $\left(\mathrm{m}^{2} \mathrm{~s}^{-1}\right)$ & $5 \times 10^{-6}$ \\
\hline$\omega:$ mean molecular velocity $\left(\mathrm{m} \mathrm{s}^{-1}\right)$ & $\sqrt{\frac{\delta M 1}{\pi M W_{\text {vor }}}}$ \\
\hline$R$ : gas constant $\left(\mathrm{kg} \mathrm{m}^{2} \mathrm{~s}^{-2} \mathrm{~K}^{-1} \mathrm{~mol}^{-1}\right)$ & 8.314 \\
\hline$M W_{w}$ : average molecular weight of $\mathrm{FEP}^{3}\left(\mathrm{~g} \mathrm{~mol}^{-1}\right)$ & 200 \\
\hline $\begin{array}{l}M W_{v o c}: \text { vapor molecular weight }\left(\mathrm{g} \mathrm{mol}^{-1}\right) \\
\theta: \text { molecular volume }\left(\mathrm{cm}^{3} \mathrm{~mol}^{-1}\right)\end{array}$ & $\begin{array}{l}\text { species dependent } \\
\text { species dependent (Fig. 3) }\end{array}$ \\
\hline
\end{tabular}

${ }^{a}$ The parameters listed here correspond to the dynamic system $\mathrm{X} \underset{\mathrm{k}_{-1}}{\stackrel{\mathrm{k}_{1}}{\rightleftharpoons}} \mathrm{Y} \stackrel{\mathrm{k}_{2}}{\longrightarrow} \mathrm{Z}$, where $\mathrm{X}$ is the species of interest. Detailed discussion of the incorporation of this model framework into chamber models can be found in SI. VII. ${ }^{b}$ It is recommended to fit the measured signal decay of species $\mathrm{X}$ to the analytical equation in SI. VI to obtain $\mathrm{k}_{2}$, or simply use the asymptotic relationship $k_{w}^{X}=\frac{K_{e q}}{1+K_{e q}} \mathrm{k}_{2}$, where $k_{w}^{X}$ is the "apparent" first-order decay rate constant of species $\mathrm{X}$, and $K_{e q}=\frac{\mathrm{k}_{1}}{\mathrm{k}_{-1}}$. In general, the use of the asymptote will not lead to a significant difference if the measurement lasts several hours. 

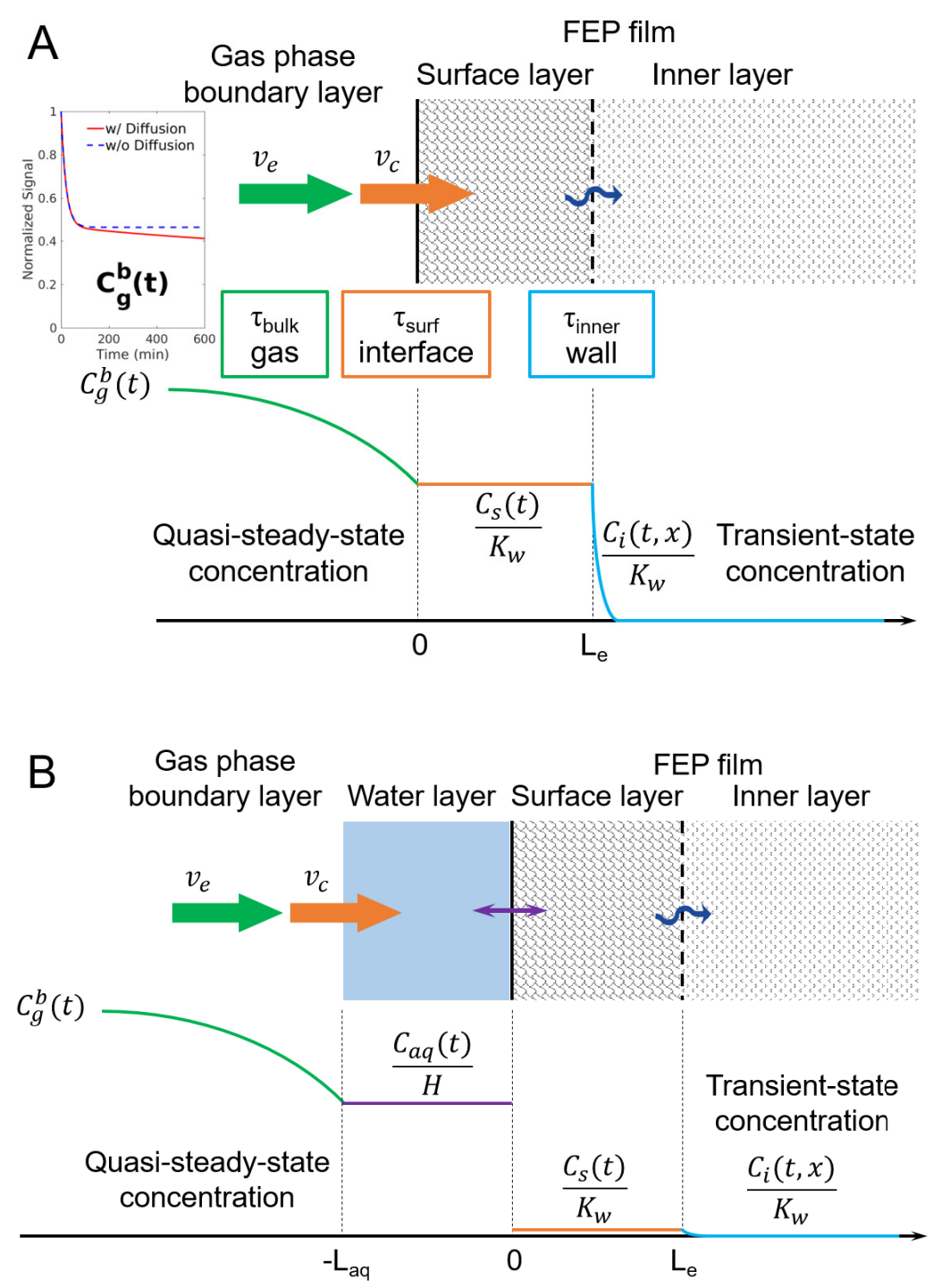

Figure 1: Two-layer (dry) and three-layer (moist) models of vapor uptake at the surface of Teflon film in a laboratory chamber. (A) Two-layer kinetic sorption model. $v_{e}$ and $v_{c}$ are gas-phase boundary layer and interfacial mass transport coefficients, respectively. $C_{g}^{b}(t)$ is the bulk gas-phase concentration, $C_{s}(t)$ is the concentration (assumed to rapidly achieve uniformity) within the Surface Layer, and $C_{i}$ is the transient concentration in the Inner Layer. The vapor-Teflon wall equilibrium constant, $K_{w}$, plays a role similar to that of a Henry's law dissolution constant. Time scales, $\tau_{\text {bulk }}, \tau_{\text {surf }}$, and $\tau_{\text {inner }}$, corresponding to each layer are indicated. (B) Vapor uptake process in the presence of a thin aqueous film on the Teflon wall. Assumption of $H \gg K_{w}$, where $H$ is the corresponding Henry's Law constant, is made. $C_{a q}(t)$ denotes the concentration of dissolved vapor in the aqueous film. $L_{e}$ and $L_{a q}$ represent the surface layer and aqueous film thicknesses, respectively. 


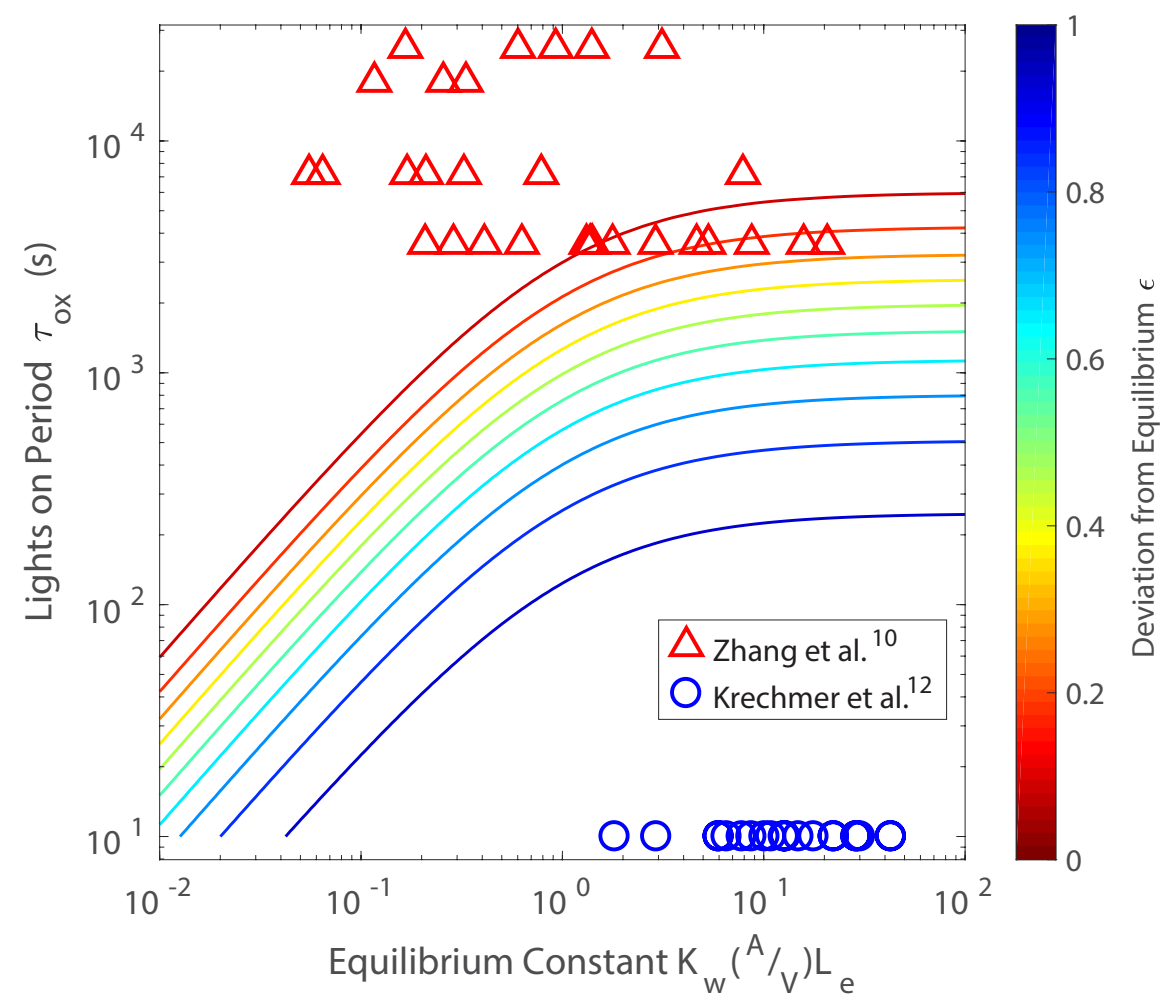

Figure 2: Deviation from equilibrium state at the end of oxidation period $\tau_{\text {ox }}$ as a function of equilibrium constant $K_{w} \frac{A}{V} L_{e}$ and oxidation period $\tau_{\mathrm{ox}}$ for the system represented by $\mathrm{G} \stackrel{\mathrm{k}_{0}}{\longrightarrow} \mathrm{X} \underset{\mathrm{k}_{-1}}{\stackrel{\mathrm{k}_{1}}{\rightleftharpoons}} \mathrm{Y}$, where $\mathrm{k}_{0}=\frac{0.05}{\tau_{\mathrm{ox}}}\left(\mathrm{s}^{-1}\right.$, assume $5 \%$ of $\mathrm{G}$ is consumed at the end of oxidation period $\left.\tau_{\mathrm{ox}}\right), \mathrm{k}_{1}=\frac{A}{V} v_{l}\left(\mathrm{~s}^{-1}\right), \mathrm{k}_{-1}=\frac{1}{L_{e} K_{w}} v_{l}\left(\mathrm{~s}^{-1}\right), \frac{A}{V}$ is the surface area to volume ratio of the chamber $\left(\mathrm{m}^{-1}\right), v_{l}$ is the vapor-to-wall mass transport coefficient $\left(\mathrm{m} \mathrm{s}^{-1}\right), L_{e}$ is the surface layer thickness $(\mathrm{m}), K_{w}$ is the dissolution equilibrium constant of vapor molecule in Teflon film. The equilibrium constant $K_{e q}=\frac{\mathrm{k}_{1}}{\mathrm{k}_{-1}}=K_{w} \frac{A}{V} L_{e}$. 
A

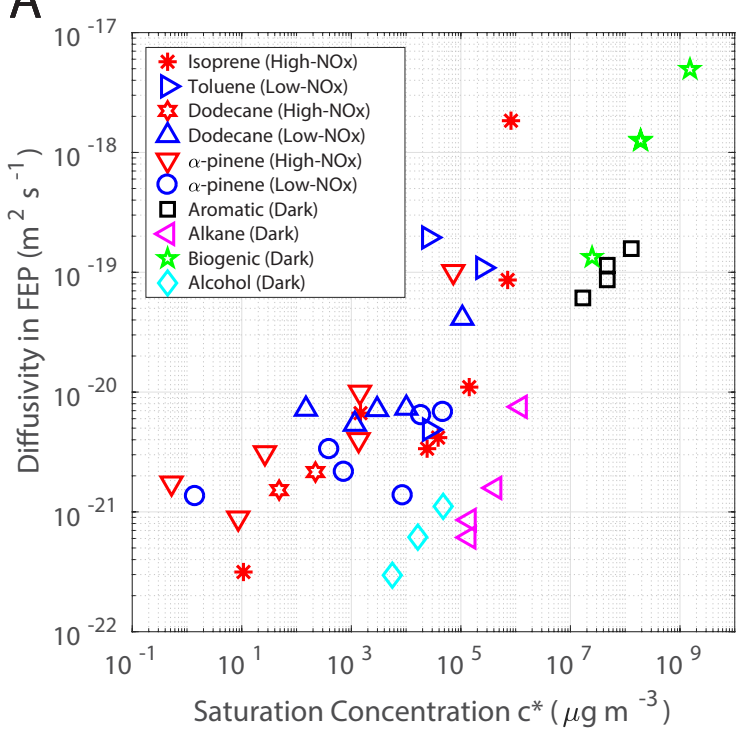

B



Figure 3: (A) Diffusivity in FEP film inferred from measurements by Zhang et al. ${ }^{10}$ using CIMS and from this study using GC/FID as a function of saturation concentration $\left(c^{*}\right)$ predicted by EVAPORATION. ${ }^{23,24}$ (B) Comparison between measured and fitted diffusivity $\left(\mathcal{D}_{\text {eff }}\right.$ in $\left.\mathrm{m}^{2} \mathrm{~s}^{-1}\right)$ in Teflon film. The molecular volume $\left(\theta \mathrm{in} \mathrm{cm}^{3} \mathrm{~mol}^{-1}\right)$ and saturation vapor concentration $\left(c^{*}\right.$ in $\mu \mathrm{g} \mathrm{m}^{-3}$ ) dependent fitting equation in (B) is used. Molecular volume is estimated by summing the characteristic atomic volumes $(\theta=\mathrm{C} \times 16.35+\mathrm{H} \times 8.71$ $+\mathrm{O} \times 12.43+\mathrm{N} \times 14.39 \mathrm{~cm}^{3} \mathrm{~mol}^{-1}$, where $\mathrm{C}, \mathrm{H}, \mathrm{O}$, and $\mathrm{N}$ represent the number of carbon, hydrogen, oxygen, and nitrogen atoms in the compound). ${ }^{44}$ Note: this equation applies only for molecules with volume exceeding $110.9 \mathrm{~cm}^{3} \mathrm{~mol}^{-1}$. 



Figure 4: Signal decay after $20 \mathrm{~s}$ of in situ generation of isoprene oxidation products: (A) $\mathrm{C}_{5} \mathrm{H}_{8} \mathrm{O}_{2}$ and $(\mathrm{B}) \mathrm{C}_{5} \mathrm{H}_{9} \mathrm{O}_{4} \mathrm{~N}$ at $\mathrm{RH}=5 \%, 50 \%$ and $>90 \%$ (with aqueous film). Because of the signal decay caused by the "memory effect" arising from the sampling tube and instrument inlet, ${ }^{40}$ the peaks show up $\sim 5$ min after lights off. 


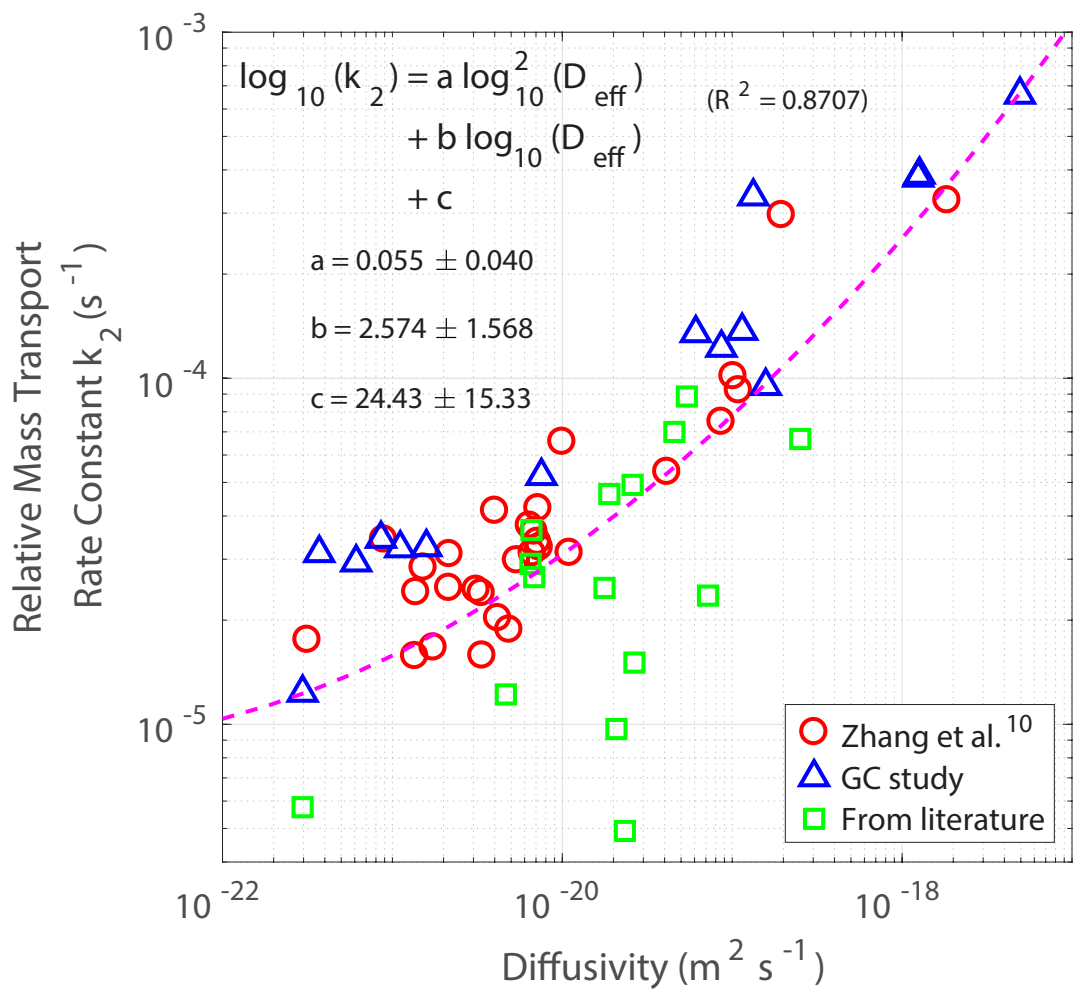

Figure 5: Empirical relationship between compound molecular diffusivity $\mathcal{D}_{\text {eff }}\left(\mathrm{m}^{2} \mathrm{~s}^{-1}\right)$ and relative inner layer mass transport rate constant $\mathrm{k}_{2}\left(\mathrm{~s}^{-1}\right) . \mathrm{k}_{2}$ is derived by fitting the analytical solution in SI.V to the experimental data, whereas data points from the literature $2,28,30-33,35,36$ are calculated by the asymptotic relationship between $k_{w}$ (reported data) and $\mathrm{k}_{2}$. Diffusivity is predicted by the equation in Fig. 3 . 


\section{Acknowledgement}

This work was supported by National Science Foundation grant AGS-1523500. RZ was supported by Natural Science and Engineering Research Council of Canada Postdoctoral Fellowship (NSERC-PDF). SMC was supported by National Science Foundation Graduate Research Fellowship (No. 1745301).

\section{Supporting Information Available}

The supplementary material contains discussion of (I) the timescale of gas-phase boundary layer transport, (II) parameterization of the activity and accommodation coefficients in the surface layer absorption, (III) the analytical solution for the kinetics of the system $\mathrm{G} \stackrel{\mathrm{k}_{0}}{\longrightarrow}$ $\mathrm{X} \underset{\mathrm{k}_{-1}}{\stackrel{\mathrm{k}_{1}}{\rightleftharpoons}} \mathrm{Y},(\mathrm{IV})$ diffusivities in fresh and aged Teflon chambers, (V) the humidity effect on Teflon inner layer diffusivity, (VI) the exact and approximate solutions for the kinetics of the system $\mathrm{X} \underset{\mathrm{k}_{-1}}{\stackrel{\mathrm{k}_{1}}{\rightleftharpoons}} \mathrm{Y} \stackrel{\mathrm{k}_{2}}{\longrightarrow} \mathrm{Z}$, and (VII) the application of the two-layer framework in chamber simulations.

This material is available free of charge via the Internet at http://pubs.acs.org/.

\section{References}

(1) Schwantes, R. H.; McVay, R. C.; Zhang, X.; Coggon, M. M.; Lignell, H.; Flagan, R. C.; Wennberg, P. O.; Seinfeld, J. H. Advances in Atmospheric Chemistry; World Scientific, 2017; Chapter 1 Science of the Environmental Chamber, pp 1-93.

(2) Loza, C. L.; Chan, A. W. H.; Galloway, M. M.; Keutsch, F. N.; Flagan, R. C.; Seinfeld, J. H. Characterization of vapor wall loss in laboratory chambers. Environ. Sci. Technol. 2010, 44, 5074-5078.

(3) Matsunaga, A.; Ziemann, P. J. Gas-wall partitioning of organic compounds in a Teflon 
film chamber and potential effects on reaction product and aerosol yield measurements. Aerosol Sci. Technol. 2010, 44, 881-892.

(4) McVay, R. C.; Cappa, C. D.; Seinfeld, J. H. Vapor-wall deposition in chambers: Theoretical considerations. Environ. Sci. Technol. 2014, 48, 10251-10258.

(5) Yeh, G. K.; Ziemann, P. J. Alkyl nitrate formation from the reactions of C8-C14 nalkanes with $\mathrm{OH}$ radicals in the presence of $\mathrm{NOx}$ : Measured yields with essential corrections for gas-wall partitioning. J. Phys. Chem. A 2014, 118, 8147-8157.

(6) Zhang, X.; Cappa, C. D.; Jathar, S. H.; McVay, R. C.; Ensberg, J. J.; Kleeman, M. J.; Seinfeld, J. H. Influence of vapor wall loss in laboratory chambers on yields of secondary organic aerosol. Proc. Natl. Acad. Sci. U. S. A. 2014, 111, 5802-5807.

(7) Bian, Q.; May, A. A.; Kreidenweis, S. M.; Pierce, J. R. Investigation of particle and vapor wall-loss effects on controlled wood-smoke smog-chamber experiments. Atmos. Chem. Phys. 2015, 15, 11027-11045.

(8) Krechmer, J. E. et al. Formation of low volatility organic compounds and secondary organic aerosol from isoprene hydroxyhydroperoxide low-NO oxidation. Environ. Sci. Technol. 2015, 49, 10330-10339.

(9) Yeh, G. K.; Ziemann, P. J. Gas-wall partitioning of oxygenated organic compounds: Measurements, structure-activity relationships, and correlation with gas chromatographic retention factor. Aerosol Sci. Technol. 2015, 49, 727-738.

(10) Zhang, X.; Schwantes, R. H.; McVay, R. C.; Lignell, H.; Coggon, M. M.; Flagan, R. C.; Seinfeld, J. H. Vapor wall deposition in Teflon chambers. Atmos. Chem. Phys. 2015, $15,4197-4214$.

(11) Cappa, C. D.; Jathar, S. H.; Kleeman, M. J.; Docherty, K. S.; Jimenez, J. L.; Seinfeld, J. H.; Wexler, A. S. Simulating secondary organic aerosol in a regional air quality 
model using the statistical oxidation model - Part 2: Assessing the influence of vapor wall losses. Atmos. Chem. Phys. 2016, 16, 3041-3059.

(12) Krechmer, J. E.; Pagonis, D.; Ziemann, P. J.; Jimenez, J. L. Quantification of gaswall partitioning in Teflon environmental chambers using rapid bursts of low-volatility oxidized species generated in situ. Environ. Sci. Technol. 2016, 50, 5757-5765.

(13) La, Y. S.; Camredon, M.; Ziemann, P. J.; Valorso, R.; Matsunaga, A.; Lannuque, V.; Lee-Taylor, J.; Hodzic, A.; Madronich, S.; Aumont, B. Impact of chamber wall loss of gaseous organic compounds on secondary organic aerosol formation: explicit modeling of SOA formation from alkane and alkene oxidation. Atmos. Chem. Phys. 2016, 16, $1417-1431$.

(14) Nah, T.; McVay, R. C.; Zhang, X.; Boyd, C. M.; Seinfeld, J. H.; Ng, N. L. Influence of seed aerosol surface area and oxidation rate on vapor wall deposition and SOA mass yields: a case study with $\alpha$-pinene ozonolysis. Atmos. Chem. Phys. 2016, 16, 93619379.

(15) Trump, E. R.; Epstein, S. A.; Riipinen, I.; Donahue, N. M. Wall effects in smog chamber experiments: A model study. Aerosol Sci. Technol. 2016, 50, 1180-1200.

(16) Ye, P.; Ding, X.; Hakala, J.; Hofbauer, V.; Robinson, E. S.; Donahue, N. M. Vapor wall loss of semi-volatile organic compounds in a Teflon chamber. Aerosol Sci. Technol. 2016, 50, 822-834.

(17) Crank, J. A theoretical investigation of the influence of molecular relaxation and internal stress on diffusion in polymers. J. Polym. Sci. 1953, 11, 151-168.

(18) Seinfeld, J. H.; Pankow, J. F. Organic atmospheric particulate material. Annu. Rev. Phys. Chem. 2003, 54, 121-140. 
(19) Boedeker, PTFE, FEP, and PFA Specifications. http://www.boedeker.com/feppfa_ p.htm.

(20) Frezzotti, A. Boundary conditions at the vapor-liquid interface. Phys. Fluids 2011, 23, 030609.

(21) Davidovits, P.; Jayne, J. T.; Duan, S. X.; Worsnop, D. R.; Zahniser, M. S.; Kolb, C. E. Uptake of gas molecules by liquids: a model. J. Phys. Chem. 1991, 95, 6337-6340.

(22) Tokarev, A.; Friess, K.; Machkova, J.; S̆ipek, M.; Yampolskii, Y. Sorption and diffusion of organic vapors in amorphous Teflon AF2400. J. Polym. Sci. Pol. Phys. 2006, 44, $832-844$.

(23) Tropo, Vapour pressure of Pure Liquid Organic Compounds. http://tropo. aeronomie.be/models/evaporation_run.htm.

(24) Compernolle, S.; Ceulemans, K.; Müller, J.-F. EVAPORATION: a new vapour pressure estimation method for organic molecules including non-additivity and intramolecular interactions. Atmos. Chem. Phys. 2011, 11, 9431-9450.

(25) Frisch, H. L. Sorption and transport in glassy polymers - a review. Polym. Eng. Sci. 1980, 20, 2-13.

(26) Vieth, W.; Howell, J.; Hsieh, J. Dual sorption theory. J. Membr. Sci. 1976, 1, 177 220.

(27) Shiraiwa, M.; Ammann, M.; Koop, T.; Pöschl, U. Gas uptake and chemical aging of semisolid organic aerosol particles. Proc. Natl. Acad. Sci. U. S. A. 2011, 108, 1100311008.

(28) Shiraiwa, M.; Yee, L. D.; Schilling, K. A.; Loza, C. L.; Craven, J. S.; Zuend, A.; Ziemann, P. J.; Seinfeld, J. H. Size distribution dynamics reveal particle-phase chemistry in organic aerosol formation. Proc. Natl. Acad. Sci. U. S. A. 2013, 110, 11746-11750. 
(29) Schwarzenbach, R. P.; Gschwend, P. M.; Imboden, D. M. Environmental Organic Chemistry, 2nd ed.; John Wiley \& Sons, Inc.: Hoboken, New Jersey, 2005.

(30) Praske, E.; Crounse, J. D.; Bates, K. H.; Kurtén, T.; Kjaergaard, H. G.; Wennberg, P. O. Atmospheric fate of methyl vinyl ketone: Peroxy radical reactions with NO and HO2. J. Phys. Chem. A 2015, 119, 4562-4572.

(31) Schwantes, R. H.; Teng, A. P.; Nguyen, T. B.; Coggon, M. M.; Crounse, J. D.; St. Clair, J. M.; Zhang, X.; Schilling, K. A.; Seinfeld, J. H.; Wennberg, P. O. Isoprene $\mathrm{NO}_{3}$ oxidation products from the $\mathrm{RO}_{2}+\mathrm{HO}_{2}$ pathway. J. Phys. Chem. A 2015, 119, 10158-10171.

(32) St. Clair, J. M.; Rivera-Rios, J. C.; Crounse, J. D.; Knap, H. C.; Bates, K. H.; Teng, A. P.; Jrgensen, S.; Kjaergaard, H. G.; Keutsch, F. N.; Wennberg, P. O. Kinetics and products of the reaction of the first-generation isoprene hydroxy hydroperoxide (ISOPOOH) with OH. J. Phys. Chem. A 2016, 120, 1441-1451.

(33) Schwantes, R. H.; Schilling, K. A.; McVay, R. C.; Lignell, H.; Coggon, M. M.; Zhang, X.; Wennberg, P. O.; Seinfeld, J. H. Formation of highly oxygenated low-volatility products from cresol oxidation. Atmos. Chem. Phys. 2017, 17, 3453-3474.

(34) Teng, A. P.; Crounse, J. D.; Wennberg, P. O. Isoprene peroxy radical dynamics. J. Am. Chem. Soc. 2017, 139, 5367-5377.

(35) Bates, K. H.; Crounse, J. D.; St. Clair, J. M.; Bennett, N. B.; Nguyen, T. B.; Seinfeld, J. H.; Stoltz, B. M.; Wennberg, P. O. Gas phase production and loss of isoprene epoxydiols. J. Phys. Chem. A 2014, 118, 1237-1246.

(36) Loza, C. L.; Craven, J. S.; Yee, L. D.; Coggon, M. M.; Schwantes, R. H.; Shiraiwa, M.; Zhang, X.; Schilling, K. A.; Ng, N. L.; Canagaratna, M. R.; Ziemann, P. J.; Flagan, R. C.; Seinfeld, J. H. Secondary organic aerosol yields of 12-carbon alkanes. Atmos. Chem. Phys. 2014, 14, 1423-1439. 
(37) Nguyen, T. B.; Coggon, M. M.; Bates, K. H.; Zhang, X.; Schwantes, R. H.; Schilling, K. A.; Loza, C. L.; Flagan, R. C.; Wennberg, P. O.; Seinfeld, J. H. Organic aerosol formation from the reactive uptake of isoprene epoxydiols (IEPOX) onto non-acidified inorganic seeds. Atmos. Chem. Phys. 2014, 14, 3497-3510.

(38) Nguyen, T. B. et al. Atmospheric fates of Criegee intermediates in the ozonolysis of isoprene. Phys. Chem. Chem. Phys. 2016, 18, 10241-10254.

(39) Crounse, J. D.; McKinney, K. A.; Kwan, A. J.; Wennberg, P. O. Measurement of gasphase hydroperoxides by chemical ionization mass spectrometry. Anal. Chem. 2006, 78, 6726-6732.

(40) Pagonis, D.; Krechmer, J. E.; de Gouw, J.; Jimenez, J. L.; Ziemann, P. J. Effects of gaswall partitioning in Teflon tubing and instrumentation on time-resolved measurements of gas-phase organic compounds. Atmos. Meas. Tech. 2017, 10, 4687-4696.

(41) Taylor, W. D.; Allston, T. D.; Moscato, M. J.; Fazekas, G. B.; Kozlowski, R.; Takacs, G. A. Atmospheric photodissociation lifetimes for nitromethane, methyl nitrite, and methyl nitrate. Int. J. of Chem. Kinet. 1980, 12, 231-240.

(42) Lee, B. H.; Lopez-Hilfiker, F. D.; Mohr, C.; Kurtn, T.; Worsnop, D. R.; Thornton, J. A. An Iodide-adduct high-resolution time-of-flight chemical-ionization mass spectrometer: Application to atmospheric inorganic and organic compounds. Environ. Sci. Technol. 2014, 48, 6309-6317.

(43) Bagley, E.; Long, F. A. Two-stage sorption and desorption of organic vapors in cellulose acetate $^{1,2}$. J. Am. Chem. Soc. 1955, 77, 2172-2178.

(44) Abraham, M. H.; McGowan, J. C. The use of characteristic volumes to measure cavity terms in reversed phase liquid chromatography. Chromatographia 1987, 23, 243-246. 
(45) Linossier, I.; Gaillard, F.; Romand, M.; Feller, J. F. Measuring water diffusion in polymer films on the substrate by internal reflection fourier transform infrared spectroscopy. J. Appl. Polym. Sci. 1997, 66, 2465-2473.

(46) Bean, J. K.; Hildebrandt Ruiz, L. Gas-particle partitioning and hydrolysis of organic nitrates formed from the oxidation of $\alpha$-pinene in environmental chamber experiments. Atmos. Chem. Phys. 2016, 16, 2175-2184. 


\section{Graphical TOC Entry}

560

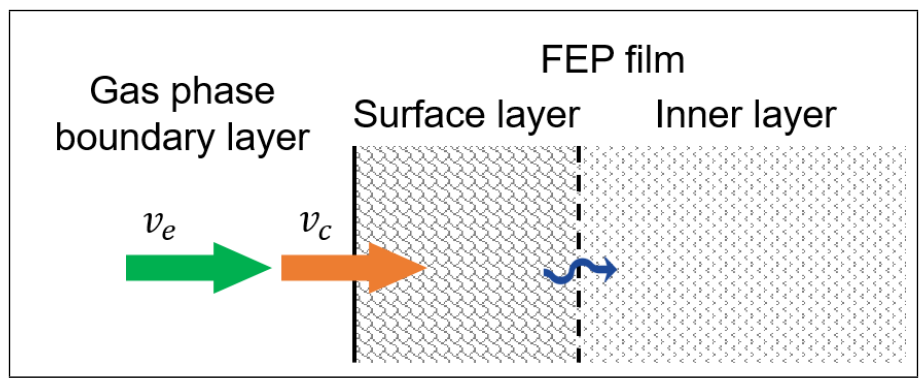




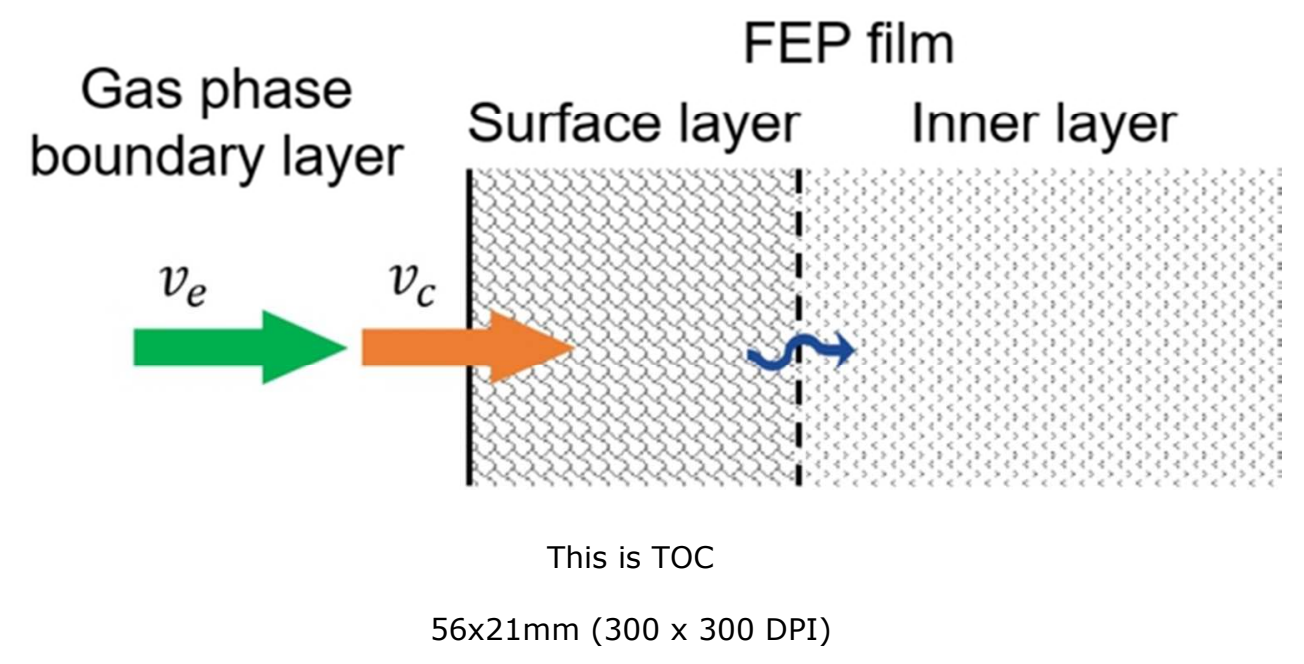

